\title{
Speech Communication in Teaching a Foreign Language
}

\author{
Hikmatova M.N.
}

\begin{abstract}
A language is considered not only and not so much as a system of organized levels, but primarily as a system of a number of sub-languages or modules, each of which, in turn, has a system organization. Thus, a nominative language system can be described using a system of modules. One of the main modules in the system of any developed language is the sublanguage of everyday communication.The article deals with interpersonal communication in teaching foreign languages.
\end{abstract}

Keywords : oral speech, activity, modern lingvistics, language sense, language action, motivation, communicant, statement, intention, condition, implication.

\section{INTRODUCTION}

$\mathrm{S}$ peech communication is the most complex type of human activity, which involves a high degree of development of speech ability. Its main unit today is recognized as an oral dialogical text - discourse. When learning a foreign language, great attention should be paid to everyday speech communication in various spheres of human life. The task of intensifying this aspect of training has put linguists in need of developing a scientific basis for describing interpersonal speech communication with the simultaneous creation of practical sources containing relevant information.

In accordance with the linguistic ideas of recent times, a language is considered not only and not so much as a system of organized levels, but primarily as a system of a number of sub-languages or modules, each of which, in turn, has a system organization. Thus, a nominative language system can be described using a system of modules. One of the main modules in the system of any developed language is the sublanguage of everyday communication.

\section{LITERATURE REVIEW}

Turning to theory seems very productive in terms of the prospects for teaching a foreign language. F. Kiefer distinguishes between three main types of situational statements, which he considers as elementary units of the description of everyday communication, oriented on the theory of frames.

\section{METHODS}

The speech action can formally be represented by the following components: $\mathrm{RD}=(\mathrm{B}, \mathrm{N}, \mathrm{Y}, \mathrm{C})$ where $\mathrm{RD}$ is the

Revised Manuscript Received on October 15, 2019.

* Correspondence Author

Hikmatova M.N.*, Teacher, Bukhara State University speech action, $\mathrm{B}$ is the utterance, $\mathrm{H}$ is the intention, $\mathrm{Y}$ is the condition, $\mathrm{C}$ is the consequence. The theory of speech actions establishes that they can be embodied both in a statement and in a text. The latter include such complex speech actions as narration, reasoning, description, better known in the linguistic tendency as compositional speech forms. The knowledge about it includes, first of all, information about the units that make up the sublanguage and their equivalents, about the possibility of using these units in contexts of various types, about the restrictions imposed on their use, about their potential impact on the communication partner. Knowledge of this type was traditionally called a "sense of language" and, as a rule, remained beyond the scope of a linguistic description. Modern linguistics, significantly expanding its scientific paradigm, not only included these types of knowledge in its subject, but also demanded their integration into the description of individual units of the language.

\section{ANALYSIS}

Linguists recognized the need to move from declaratively oriented directions in the lexical and syntactic organization of statements in everyday communication situations to their fullest and detailed coverage. The fact that statements of this kind occupy one of the central places in the personal vocabulary of native speakers and are a kind of "ready-made blocks" from which the building of everyday speech is built is considered to be proven today. Consequently, an inventory of such cliched expressions and the corresponding non-verbal means of communication is a very real, albeit very laborious task.

Note the factors that affect the nature of communication, primarily the social parameters of participants, as well as presuppositions regarding their knowledge, assumptions, intentions and expectations, and in the language design brevity of expression, simplicity of syntactic construction, the role of indicative language elements and non-verbal means of communication in connection with a speaking situation, clichéd language expressions. Presentation in an adequate form should contribute to the active assimilation of units of everyday speech communication by students. The concept is thus based on the concept of "language in action".

When describing a language as a speech activity, it becomes necessary to study the general laws of verbal communication, which also includes the functioning of linguistic means in real acts of communication.

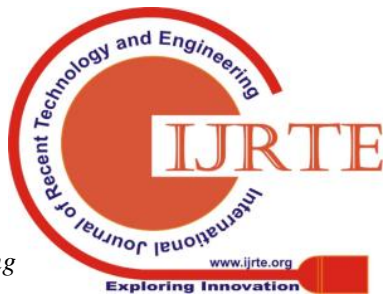
\& Sciences Publication 
The basis of this approach, taking shape in the theory of communicative linguistics, is primarily an understanding of activity. Any form of activity is predetermined by the interaction of people within society, and external factors are consciously processed on the basis of internal conditions. Thus, conditions, tasks, motivations and goals can be considered as determinants of human actions.

The category of activity is an integral part of the modern concept of linguistic knowledge. This category found expression in the theory of speech acts by J. Austin and J. Searle. Speech acts are considered as elementary communicative units; the purpose of the message is to transfer the speaker's knowledge to his partner in communication, and motivation contains incentives to perform certain intellectual or practical actions.

\section{DISCUSSION}

We see a significant achievement in the theory of speech acts in the separation of the propositional content of the utterance and its illocutionary function, in isolating in the process of communication the performers - communicants, language facts and facts of the situation.

A proposition in this context is interpreted as a stable semantic core of a statement, which includes names that are correlated with objects of reality, and predicates that can acquire modal and temporal characteristics. A proposition is characterized by conditions of truth.

The illocutionary function gives the statement purposefulness, implements goal setting, the speaker's intention, explicit or hidden goals of the statement: ask, ask, forbid. For example, the sentence: Why not? in its illocutionary function, it is not a question, but a consent. The correct interpretation of the illocutionary function provides the correct understanding - the success of the use of the utterance.

Proceeding from his intention and relying on his own knowledge fund common with the addressee, the addressee builds statements, carrying out reference and predication using various linguistic means. The main coordinates of the communicative act are the communicants: the sender and recipient of information with their social and role characteristics - and the communicative situation, for the characterization of which temporal and spatial characteristics, as well as objects and phenomena that are in the center of attention of communicants, are of particular importance. The nature of the communicative act as a whole, which includes, in addition to the purely speech series of non-verbal components, is thus determined not only by the propositional content of the utterance, but also by the social properties of the communicants and the conditions for the development of the communication situation. The need to take these parameters into account has brought to life the theory of speech actions, which has been actively developing in recent years. Orientation to speech activity involves taking into account the conditions of communication, the linguistic content of communication and the characterization of the "process of using the language" itself.

Thus, the theory of speech actions and the activity concept of language, in contrast to the theory of speech acts, more consistently and explicitly takes into account the interests of the speaking person and the conditions of communicative interaction. Based on this concept, both linguistically and methodologically oriented typologies of speech actions were developed.

Such a structure of communicative material material is determined by a set of actions that can be clothed in the form of relevant statements. For this reason, a certain typology of speech actions seems to be a necessary basis for organizing and describing language material.

What types of actions can be performed using language expressions? What rules or conditions governs the successful implementation of these actions, and what specific tools are used to do this? In order to begin to practically form the student's communicative competence, it is necessary to give at least approximate answers to these questions.

The analysis of the collected material made it possible to distinguish, in addition to the described types of speech actions (such as, for example, incentive, evaluative, communicative, contact information requests, etc.), a number of types that were practically not discussed in the specialized literature (cf., for example, such speech actions as the expression of uncertainty, doubt and disappointment, reproach, threat, a call to conscience, warnings, etc.).

Obviously, many of the speech actions of these types can be reduced to more general and already described prototypes, for example, encouraging and calming - to incentive, etc. The goal, however, is to give the speaking person the most clear and concrete recommendations for expressing his intentions and to provide the learner with the most complete foreign language and a visually structured inventory of language tools. In other words, the more specifically the types of speech actions will be formulated, the more useful and visible information the student will receive. In addition to traditional units of a linguistic description of linguistic entities, such as, for example, a word or a stable verbal complex (phraseological unit, paremia, compound term, etc.), communicative-functional units, for example, so-called situational statements, are introduced into linguistic everyday life. It is well known that certain types of utterances are quite closely tied to the corresponding situations in life and that they are used stereotypically, almost automatically, although they are often not given a report.

From this we can conclude that it is important for the methodology of teaching foreign languages: the difference in the communicative behavior of a native speaker and a foreigner consists primarily in the fact that the latter builds his statements in each situation according to the language norms known to him and violates the norms of speaking, communicative convention, while the former uses well-established, clichéd forms of everyday communication, which have long become units of a personal vocabulary for him. 
In other words, in these cases, a native speaker does not need access to a set of productive rules, he extracts the desired statement from the memory in the finished form, especially since in modern conditions of development of various forms of mass communication, the trend towards the standard has increased.

And that bread! - И то хлеб.

(разг.)

прочим... (разг.)

Splendid! - Блеск! (разг.)

By the way... - Между

What about it! - Ну и что же!

(разг.)

было! (разг.)4

Far from it! - Не тут-то

It is this fact that makes us reconsider a number of the usual provisions of linguistics and recognize the desirability of describing such statements not within the framework of grammar, but within the framework of the lexicon. This approach contributes to a clearer linking of these two components of the integral description of the language.

So, the meaning of cliched utterances is closely related to the corresponding situations and can thus be adequately described only when the necessary situational parameters are taken into account.

In other words, it takes account of the scenario of which this statement is a component. Statements of the first type are, to use traditional terminology, strongly clichéd formulas of speech etiquette, such as Thank you! Good bye! Yours sincerely! etc. .

For statements of this type, even in the traditional semantic concept, the status of lexicon units has been fixed, which are subject to the same words as lexicographic codification.

The second type includes reproducible in a ready-made and situationally related statements, which, however, from the point of view of the standard lexicological theory, are completely free combinations of words, each of which is used in its direct, i.e. directly to the nominative value, cf., for example: what you don't say doesn't hurt, etc. Although there are no traces of idiomatization here, these statements are linguistically worked out and socially fixed cliches and clichés and, from the point of view of frame theory, are as "connected" as statements of the first type.

The description of these statements in terms of the lexicon to a greater extent than their traditional interpretation as free combinations of words reflects the practical interests of teaching foreign languages, since students can assimilate statements of this type only as "ready-made entries" of their personal vocabulary, and not form them freely according to certain productive rules of the language. The third type of situational statements occupies an intermediate position between statements of the first and second types.

Statements of the third type have a certain idiomatic meaning and are correlated with traditionally distinguished phraseological expressions, since these statements are components of certain scenarios or dynamic frames and can be explained only on the basis of knowledge of the whole

situation, for example: Oh, how the World is small.

Both the meaning and the functioning of situational statements of all three types can be adequately described only on the basis of frame theory. Thus, in order to reveal the meaning of the cliché of everyday communication, including one-word ones, it is necessary to know the appropriate conditions of use, including the paralinguistic components of the situation. Paralinguisms - kinemas - automated movements that complement and replace speech actions, and sometimes are in conflict with them. These are movements and body positions, head and limb movements, as well as facial movements that have specific meanings in a particular social and cultural environment. Therefore, learning a foreign language should also include teaching socially acceptable communicative behavior. Kinemas serve to include elements of the situation, including the objective environment, and abstract concepts in communication. In conditions of lack of time or a known distance separating partners, or in conditions of mass communication, it is more convenient and economical to point out the elements of the situation, depict them or represent them symbolically than give their verbal description.

Unlike all unsigned index kinemas, correlating with various and vague phenomena of reality and not having a fixed form, symbolic kinemas appear in stereotyped codified form and correlate with a certain content of consciousness. The form of their expression is arbitrary or only indirectly related to the content. Therefore, to understand them, knowledge of the traditions of a given culture or social group is necessary, while other kinema clearly unambiguous within the communicative situation (an indication of the subject, an image of its properties). Raise the index finger - raise a hand with the index finger extended upward - a student's gesture at school to attract teacher's attention (cf. Uzbek gesture raise a hand).

Make a gesture of appreciation - a tin expressing high quality, positive assessment. The thumb and forefinger form a ring, and the remaining fingers are set apart. The hand rises to the level of the head, the palm moves slightly - back and forth, after which the hand drops.

Knocking knuckles on the table - knock your knuckles on the table. Currently less commonly used in public life: tapping the table with your knuckles, you can greet the company at a table in a cafe.

Tapping of the foot - stomping (pounding) with feet - an expression of a positive assessment, a greeting at the circus (but not at a concert). Shuffle feet - Shuffling feet - an expression of negative evaluation, possibly in a student audience. Kinemic paralinguisms contribute to the transfer of communicants' attitudes to the illocutionary function and the interpretation of this statement, on the speaker's attitude: 1. To reality 2 . To the content of the message 3 . To the addressee - and more broadly pragmatic information. 


\section{Speech Communication in Teaching a Foreign Language}

Frames and scenarios are considered in this way as research tools. Using a description based on the theory of frames, not only linguistic, but also paralinguistic, cognitive and interactive components of communicative competence of native speakers can be presented in an accessible form for study.

Situational statements, correlated with various language cliches and clichés, for their characterization in the paradigm of frame semantics, also need to address phraseological problems. This is primarily about the so-called communicative formulas or pragmatic idioms.

A joke is a joke - шутка за шуткой...

Are you out of your mind? - Да ты в уме?

That's how it is! - Вот оно что!

Unlike "normal" units of nomination, situational statements are often devoid of a clearly defined semantic core, i.e. they discover, as already noted above, a "situationally connected", "frame-oriented" meaning. In interpersonal communication, not only Congratulations type cliches are used, but also stable verbal complexes (USC) of other classes, up to "classical" idioms or phraseological units proper, on the one hand, and practically "free", although regularly reproduced word combinations (cf. situational statements of the second type, according to F. Kiefer) - on the other.

It can be argued that situational statements are by far the least studied of all phraseological classes and categories, despite their significant communicative-pragmatic relevance. In existing well-known phraseological concepts, they are assigned only a peripheral place and they are not described in traditional phraseological dictionaries. Thus, an attempt to describe and interpret them in the aspect of functioning in interpersonal communication seems to be very timely.

With a communicative-functional approach, it is not so important what place this or that statement occupies in various classifications of USK and whether it can even be considered as USK, since statements are not so rare and monotonous, for example, Because of me! Enough! Incredibly! - It is much more important to determine whether a given statement is a representative of a particular speech action. Thus, within one frame for expressing one speech action, such units may differ that are different from the nominative-taxonomic point of view, such as:That is hopeless - Это безнадежно.

I am lost! - Пропала моя голова!

But all for nothing! - Все напрасно!

The criterion that allows us to attribute the listed units to one speech action - Resignation, is of a functional-active nature. As further examples of the rubrication of linguistic material by types of speech actions can serve:

Doubt: That is in the stars. How to take it. Let's see what happens.

Threat: I will complain. You will definitely regret it. I wouldn't advice you.

Encouragement: I think you can do it. Don't worry!

The cited language material makes it possible to verify that speech actions are always communicatively meaningful, i.e. can be understood and interpreted; they can be implemented by elements of various sign systems, including paralinguistic ones. Fulfilling informational expectations of communicants, speech actions form a dialogical text. In conclusion, let us once again dwell on the types of knowledge necessary for the correct use of situational statements - a cliche in interpersonal communication.

This is actually linguistic knowledge - about the functional-stylistic and emotive characteristics that are characteristic of both a situational cliche and its translation into the native language. Further, this is extralinguistic knowledge of the respective frames or scenarios, for example, the situation of a telephone conversation. Linguistic and regional information may be relevant here, since in some cases the scenario deployment procedure may bear national cultural features. Wed The scenario of a telephone conversation in English-speaking countries, necessarily opening with a presentation such as:

Hello, this is ... (name/company name), while the corresponding Russian-language script is deployed differently, for example: Hello! Please call N.!

Linguistic and scientific information also includes knowledge about the use of Kinem: while Click with fingers, it is used as a gesture of attracting attention, for example, a waiter in a restaurant, etc. , in the Uzbek tradition, the meaning of the "click your fingers" gesture is an expression of joy, approval, as well as annoyance and error. The typology of speech actions proposed in the framework of the stated concept is empirical. This is seen as an important advantage of the present approach, both in the didactic-methodological and in theoretical terms. The goal to reduce all empirically identified types of speech actions to certain prototypical dynamic concepts - has not yet been set. This possibility, however, seems quite real, and probably the development of such a hierarchically ordered typology will constitute the main task of the next stage of the theoretical interpretation of the collected empirical material. Incidentally, this is one of the most important differences between the inductive research method and the deductive one. With a deductive approach, the starting point of the study is a kind of closed inventory of prototypical concepts, but we see the identification of such an inventory as the ultimate goal of the study.

\section{Conclusion}

A language is considered not only and not so much as a system of organized levels, but primarily as a system of a number of sub-languages or modules, each of which, in turn, has a system organization. Thus, a nominative language system can be described using a system of modules. One of the main modules in the system of any developed language is the sublanguage of everyday communication .The article deals with interpersonal communication in teaching foreign languages.

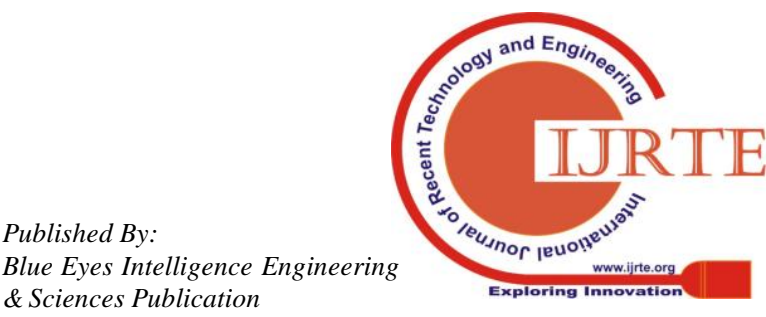




\section{REFERENCES}

1. Kiefer F. How to account for situational meaning? // Quaderni di semantic. -1985. - Vol. 6. - No. 2. - p. 288-295.

2. Leontiev A.N. General concept of activity // Fundamentals of the theory of speech activity. - M., 2002.

3. Searle J., Vanderwecken D. Basic concepts of the calculus of speech acts // New in foreign linguistics: The logical analysis of natural language. M., 2005 .-- p.242-263.

4. Britannica. Great Encyclopedic Dictionary. Reference Edition. - M .: Astrel Publishing House LLC: AST Publishing House, 2009.

5. Rubinstein S.L. Fundamentals of General Psychology. P., 2002 .-p.15-24.

6. Akhmedova Mehrinigor, Baqoyeva Muhabbat. Analysis of "Spirituality" Category and its Structure in the English Language. International Journal of Innovative Technology and Exploring Engineering (IJITEE) ISSN: 2278-3075, Volume-8, Issue-9S3, July 2019

7. Kholikova Nozima Nematilloyevna, Saidov Khayrulla Shavkatovich.Observation and Analysis of the Peculiarities of English and Uzbek Detective Genre (in the Examples of J.H.Chase's Works. International Journal of Innovative Technology and Exploring Engineering (IJITEE) ISSN: 2278-3075, Volume-8, Issue-9S3, July 2019

8. Kadirova N. S, Akhmedova Sh.N. Style and skill: critic's artistic ability. International Journal of Innovative Technology and Exploring Engineering (IJITEE) ISSN: 2278-3075, Volume-8, Issue-9S3, July 2019 